\title{
Anthropometric Data Application in Product Design
}

\author{
Lee Young Suk and Shin Sung Heon \\ Chonnam National University and \\ *Keimyung University \\ ysl@chonnam.ac.kr
}

\begin{abstract}
:
Anthropometric data are collected and used by all types of organizations for many types of applications. These including universities, hospitals, health statistics departments, militaries, apparel companies, furniture manufacturers, automobile manufacturers, safety equipment companies, aerospace companies, and many other industries and organizations. This paper was performed to summarizes some of the objective data to get the comparison of the body shape between generations. Height, bust girth, waist girth and hip girth were used to define the body size shape. Whole data were obtained from sixty families. Height in young female from the 2002 measurement data showed greater values $3 \mathrm{~cm}$ in young aged women from 1997 measurement data. For the drop values between hip girth and bust girth, the results were $7 \mathrm{~cm}$ in twenties, $4 \mathrm{~cm}$ in fifties. This paper also will discuss some of the most important issues, how family models were changed, and any changes in how we would do this study if we were to do it over again.
\end{abstract}

\section{INTRODUCTION}

Anthropometric data are collected and used for many types of applications by all types of organizations : universities, hospitals, health statistics departments, militaries, apparel companies, furniture manufacturers, automobile manufacturers, safety equipment companies, aerospace companies, and many other industries and organizations. Most industries are interested in anthropometric data, however, their need is not only focussed on raw and/or statistical data. It is necessary to transform this data in a comprehensive and welladapted manner to facilitate its integration in the design processes by end-users. With the body shape analysis, the aim is to develop data models and software tools of an on-line world-wide information system for utilizing the latest anthropometry databases in engineering environments. So, different research issues must be addressed: identifying the end-user needs according to the products they are designing, understanding the cognitive processes of anthropometry experts when dealing with 1-D and 3-D databases, identifying a means to computationally replicate these processes, and characterizing populations of 3-D subjects in a manner that can be effectively searched and visualized, developing tools to manage the transfer to the computer aided design processes of end-users. For this worldwide studies, AOARD organized WEAR meeting groups what we began calling the Worldwide Engineering Anthropometry Resource. WEAR is something that we intended would include not only the latest $3 \mathrm{D}$ surface anthropometric data from all over the world, but also traditional anthropometric data, fit and accommodation information, analytic and software tools, and guidance or intelligent agents for using the information effectively. This paper shows the changes of the Korean family models during last six years.

\section{METHODS}

The aim is to define and compare family sizes of the Korean population, aged from 16 to 55.1997 survey data was used for the previous family model construction and 2002 data set was used for the comparison data.. Measures were made using tapes and calipers. Height, bust girth, waist girth and hip girth were used as the body shape comparison elements. Drop values between bust girth and hip girth also analyzed as the comparison elements for the body shape concept. The results are shown in Figure 1-4. 


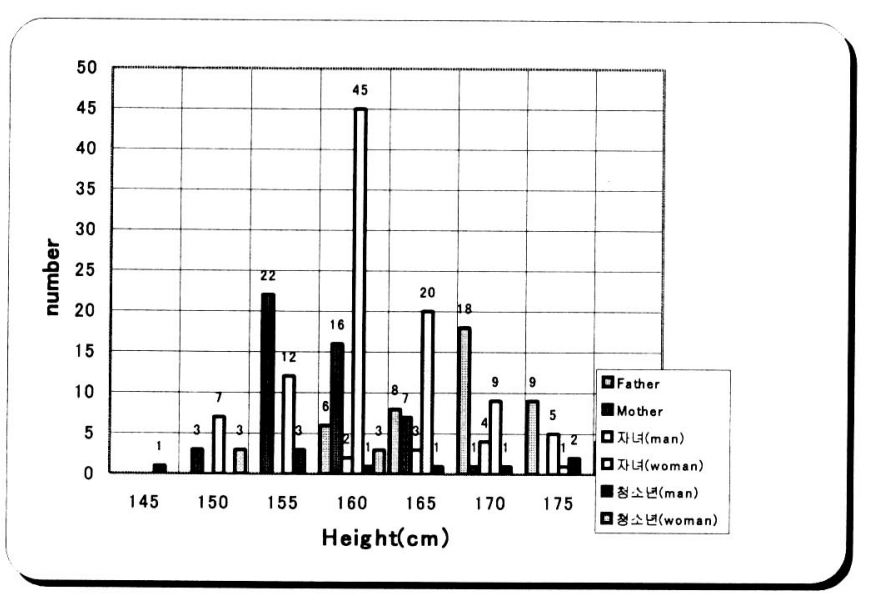

Figure1. Height Distribution

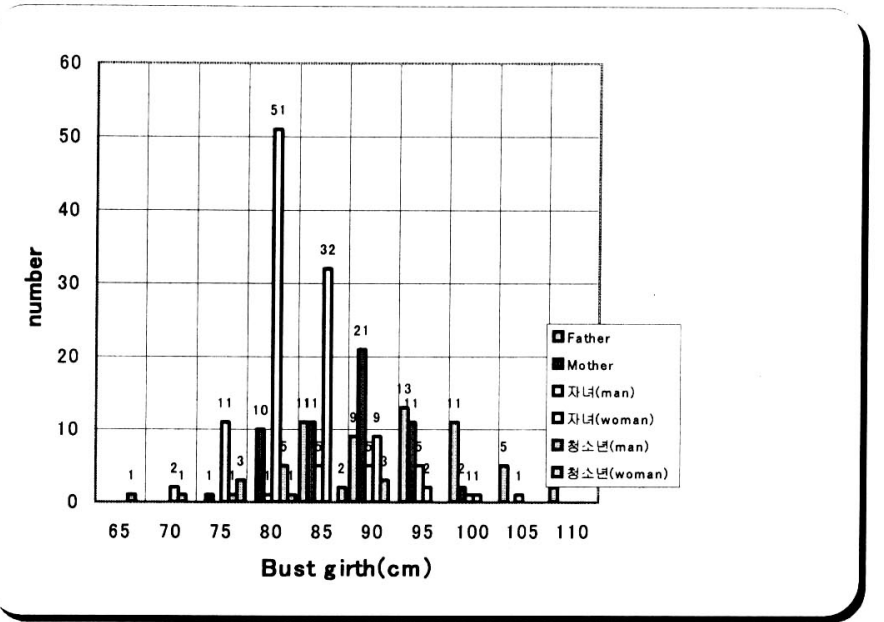

Figure 2. Bust Size Distribution

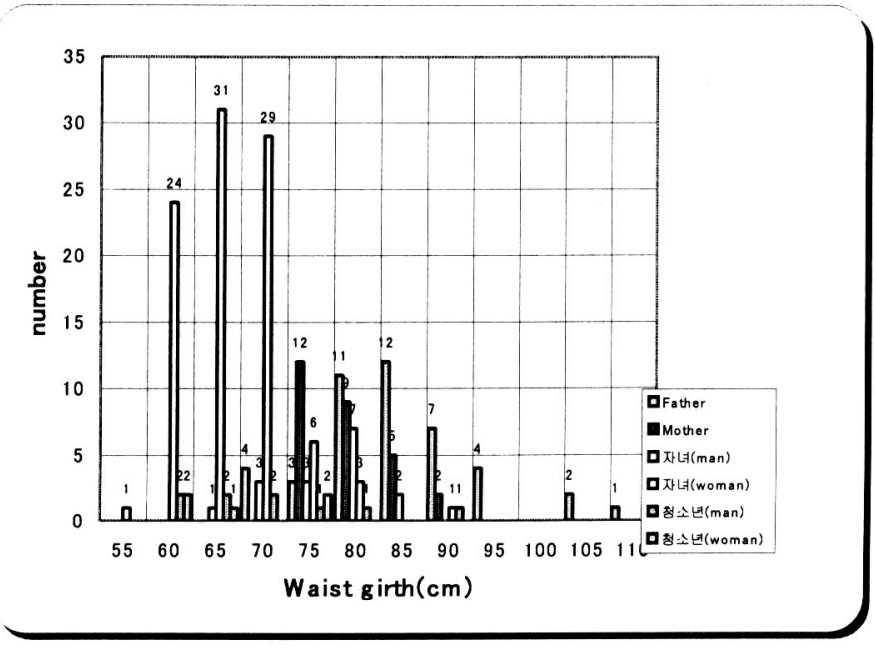

Figure 3. Waist Size Distribution

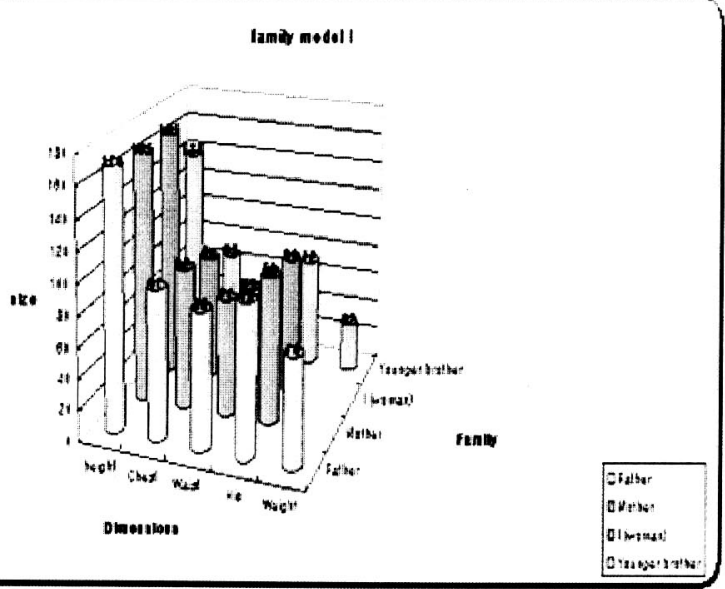

Figure 4. Family model I

\section{RESULTS}

Height in young female from the 2002 measurement data showed greater values $3 \mathrm{~cm}$ in young aged women from 1997 measurement data. For the drop values between hip girth and bust girth, the results were $7 \mathrm{~cm}$ in twenties, $4 \mathrm{~cm}$ in fifties. As shown in Fig. 4, the family model I did not show significant differences between two generations in body size. The family model II shows significant differences between mother generation and young generation in height. Up to recent times, A close examination of ergonomically relevant morphological features of man shows that it will not be possible to set up uniform metrics and functional standards for the entire world's population..

\section{REFERENCES}

Robinette, Kathleen M. 2003, Overview of the World Engineering Anthropometry Resource Objectives, Bradtmiller, B. and Gross, M.E. 1999. 3-D Whole Body Scans : Measurement Extraction Software Validation in Proceedings of the IEA 2003 International Conference, Seoul...

Régis Mollard,. 2003. How to Process Anthropometric data to fit with end-user requests, Proceedings of the IEA 2003 International Conference, Seoul .

Jurgens, H. W, 2000, Challenges of a worldwide standadization for physiological anthropometry, $5^{\text {th }}$ international congress on physiological anthropology, Seoul. 